\title{
Study of materials and manufacturing technologies for an antenna distribution network in Ka band
}

\author{
A. Tamayo Domínguez , J.M. Fernández González , J.M. Inclán Alonso , M. Sierra-Pérez
}

\begin{abstract}
A study for selecting the technology and material manufacturing for the distribution network of a low profile antenna in $\mathrm{Ka}$ band in order to provide Internet connection in commercial aircrafts through satellite link. It is presented the general structure of the network focused in new printed technologies for high frequencies such as Substrate Integrated Waveguide or Ridge Gap Waveguide. Simulated results for different dielectric materials in terms of transmission losses are provided.
\end{abstract}

Index Terms-low profile antenna, high frequency technologies, Ka band, transmission losses, substrate integrated waveguide, ridge gap waveguide, distribution network.

\section{INTRODUCTION}

This study is focused on the research of the best material and manufacturing option for the design and deployment of a reduced-sized antenna boarded in commercial aircrafts in order to provide high speed Internet connection during the flight. The connection will be performed through a satellite link in Ka band, so the antenna must be steerable and generate a radiation diagram with a narrow beamwidth. The proposed solution is to design an antenna based on an array of radiating elements with electronic phase control. However, in Ka band transmission losses are high so the design of the distribution network is critical. Due to the requirement of an antenna with small size different printed technologies will be studied, as Substrate Integrated Waveguide (SIW) [1][2], Ridge Gap Waveguide (RGW) [3][4] using PolyTetraFuoroEthylene (PTFE) or low temperature co-fired ceramic (LTCC) as substrate. Non-printed in air structures present lower losses, but they are larger and more expensive to manufacture. However, a comparison will be presented.

\section{THE DISTRIBUTION NETWORK}

As the losses in $\mathrm{Ka}$ band for the distribution network are high, the use of amplifiers becomes necessary to compensate them. Due to the high number of radiating elements, the use of one amplifier for each one of them is inviable so that the ideal solution is to divide the antenna in subarrays. Then, the distribution network is divided in two parts: a first level distribution based on a passive low loss structure that divides the input power in the subarray to each radiating element; and a second level distribution which spreads and amplifies the power to each subarray in which losses are compensated. That labeled network supposes a high reduction of active elements.

A scheme of the distribution network can be found in Fig. 1. Structures for both levels are explained with more detail below.

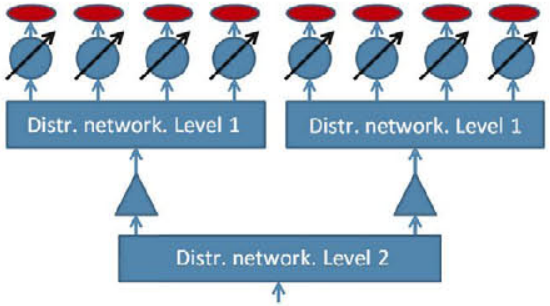

Fig. 1. Distribution network scheme.

A. Level 1. Low loss radial guide.

The radial guide is based on the excitation of a cylindrical mode in a parallel plate structure. Antennas based on these structures present very low losses and behave like a progressive-wave network along the radius of the structure, providing important manufacturing and price advantages. In Fig. 2 it is shown a simplified example of this distribution network for a subarray of four radiating elements. A detailed example of this structure with more elements is found in [5].

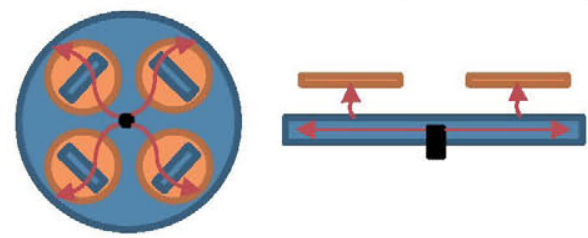

Fig. 2. Distribution network with radial guide. Level 1.

\section{B. Level 2. New printed technologies in high frequencies.}

The main objective of this paper is to study this level. The use of printed circuits in dielectric materials is a low cost and small-sized solution that allows high versatility design and manufacturing. In Fig. 3 this second level distribution network is schematized for an example of sixteen subarrays.

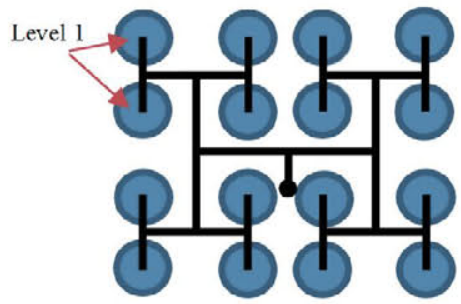

Fig. 3. Distribution network with transmission lines. Level 2. 
Most common materials for printed technology are PTFE dielectrics and LTCC with a wide range of relative dielectric constants and loss tangent. Typical printed transmission lines are strip and microstrip, but it is demonstrated that they present high losses in frequencies in $\mathrm{Ka}$ band due to the presence of the dielectric. Other technologies are proposed, such SIW or RGW. A detailed design procedure for RGW and a comparison between these technologies in terms of transmission losses are available in [6]. Simulations results in [6] shown that the lowest losses in printed technologies were achieved by RGW. Because of that, the present study will be carried out in RGW for different substrate materials. Fig. 4 shows two designs in RGW in printed technology and mechanized in air. Printed technology is cheaper than the mechanized design, but its losses are higher.
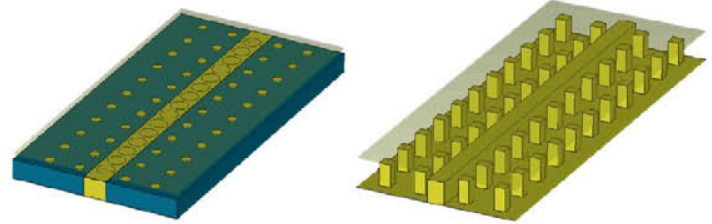

Fig. 4. RGW printed (left) and mechanized (right).

Table 1 contains the different substrates that have been used in the simulations, including the mechanized option.

TABLE I. SUBSTRATE PROPERTIES

\begin{tabular}{|c|c|c|c|}
\hline \multicolumn{4}{|c|}{ Dielectric substrates } \\
\hline Name (Number) & Type & $\varepsilon_{\mathrm{r}}$ & $\tan \delta$ \\
\hline Air (1) & Mechanized & 1 & 0 \\
\hline Taconic TacLam Plus (2) & PTFE & 2.1 & 0.0007 \\
\hline Taconic TLA-6(3) & PTFE & 2.62 & 0.002 \\
\hline Taconic RF35TC (4) & PTFE & 3.5 & 0.0011 \\
\hline Rogers FR4 (5) & PTFE/glass fiber & 4.4 & 0.018 \\
\hline Ferro A6-M(6) & LTCC & 5.9 & 0.002 \\
\hline Dupont 9k7(7) & LTCC & 7.1 & 0.001 \\
\hline Dupont 943(8) & LTCC & 7.4 & 0.0015 \\
\hline Dupont 951 (9) & LTCC & 7.8 & 0.011 \\
\hline Rogers TMM 10(10) & Hydrocarbon ceramic & 9.2 & 0.0023 \\
\hline Rogers TMM 10i (11) & Hydrocarbon ceramic & 9.8 & 0.002 \\
\hline Rogers RT/duroid 6010LM(12) & PTFE ceramic & 10.2 & 0.0023 \\
\hline
\end{tabular}

III. RESULTS

The simulations have been performed using CST software. The results for transmission losses with each substrate referenced with the number in the table are presented in Fig. 5.

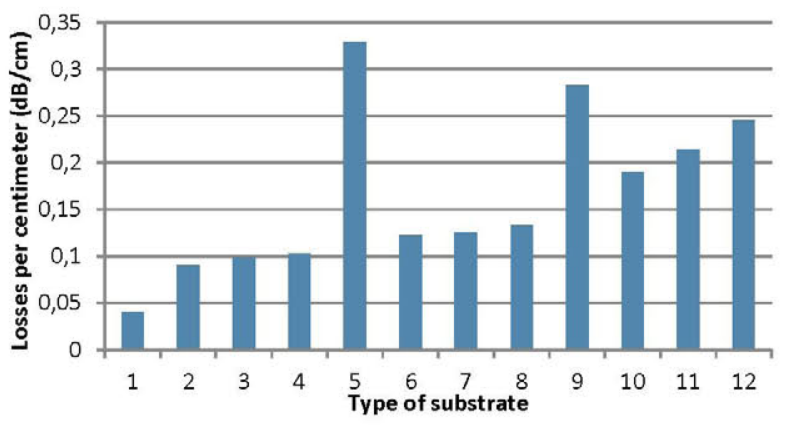

Fig. 5. Transmission losses with RGW and different dielectric substrates at $30 \mathrm{GHz}$.
As can be seen in Fig. 5, in general the higher the dielectric constant, the higher the losses because of the fact that the air gap needs to be smaller for the same bandwidth and then the field is confined in a more reduced space. This increases the dielectric losses due to the higher effective constant and the conductor losses in the ridge. It can be also observed that there are high values of losses in cases 5 and 9 that are caused by a high loss tangent of the material. The mechanized solution provides the best results with half losses compared to low dielectric constant and loss tangent substrate.

\section{Conclusions}

The losses in the distribution network for an antenna in Ka band take a critical role, even more for a large number of subarrays. It is necessary to carry out a trade-off in order to reduce the number of components needed and minimize the losses. In one hand, the use of radial guides allows the use of less active components, which suppose a cost decrease, and provides very low losses. In the other hand, transmission lines based on RGW ease to introduce amplification stages needed in the reception chain and also provides lower losses than other technologies. The mechanized case highlights due to its lowest losses, but it is necessary to have in account the relation losses-price compared with other printed options as the difference in losses can be easily compensated with the amplification stages.

\section{ACKNOWLEDGMENT}

Simulations done in this work have been performed using CST Microwave Studio Suite 2015 under a cooperation agreement between Computer Simulation Technology (CST) and Technical University of Madrid. Acknowledgement to FPI grant with reference BES-2015-075230. The authors want to acknowledge the Spanish Government, Ministry of Economy, National Program of Research, Development and Innovation for the support of the project ENABLING5G "Enabling Innovative Radio Technologies for 5G networks" (Project number TEC2014-55735-C3-1-R) and the project Spacer Debris Radar (Radar para la detección de basura espacial) from Madrid Region Government (Project number S2013/ICE3000SPADERADAR-CM).

\section{REFERENCES}

[1] M. Bozzi, L. Perregrini, K. Wu and P. Arcioni, "Current and future research trends in substrate integrated waveguide technology," Radioengineering, 2009, vol. 18, no 2, p. 201-209.

[2] T. Djerafi and K. Wu, "Substrate integrated waveguide (SIW) techniques: The state-of-the-art developments and future trends," Journal of University of Electronic Science and Technology of China, 2013, vol. 42, no 2, p. 171-192.

[3] E. Alfonso, A. Valero, J.I. Herranz, M. Baquero, M. Ferrando, V. Rodrigo, F. Vico, E. Antonino, M. Cabedo, D. Sánchez, B. Bernardo, A. Vila, "New waveguide technology for antennas and circuits," Waves, year 3, ISSN 1889-8297, 2011,pp. 65-75.

[4] E. Alfonso, M. Baquero, P.-S. Kildal, A. Valero-Nogueira, E. RajoIglesias, and J. I. Herranz, "Design of microwave circuits in ridgegap waveguide technology," in Proc. IEEE MTT-S Microw. Symp. Dig., May 2010, pp. 1544-1547.

[5] J.L. Masa-Campos, M. Sierra-Pérez, "Linearly polarized radial line patch antenna with internal rectangular coupling patches," Antennas and Propagation, IEEE Transactions on, 2011, vol. 59, no 8, p. 3049-3052.

[6] A. Tamayo, J.M. Fernández, J.M. Inclán, M. Sierra. "Design proposal for Ridge Gap Waveguide and comparison with other technologies in Ka to W bands," EuCAP, 2016. Accepted. 